\title{
RUMINATION IN CHILDREN *
}

\author{
AUGUST STRAUCH, M.D. \\ Attending Physician at the Cook County Hospital, Children's Department; \\ Instructor in Medicine (Pediatrics), Rush Medical College \\ CHICAGO
}

REPORT OF CASE

History-William L., born Oct. 6, 1918, is the only child of healthy though nervous parents. The mother is a pianist. Allaitement mixté during the first five months of life; then cow's milk alone for one month. At the age of 6 months, beef soup was repeatedly tried, but soon discontinued because with fits of anger he would persistently refuse it or spit it up. However, cereals, vegetables and fruits were taken well. At the age of nine months, beef soup was tried again and well taken and borne, if mixed with a little milk. There was never any other difficulty in feeding, except that even at the present time soup is disliked. Appetite, digestion and sleep always have been good.

At the age of 15 months (about Christmas, 1919) the boy began to spit up the orange juice that he was wont to take daily since his fourth month of life and of which he was very fond. At this time there was much drooling. At first the spitting up occurred only occasionally, but later it occurred frequently. Then the mother noticed that the boy would reswallow the orange juice after it had come up into the mouth, and that he seemed to enjoy it. $\mathrm{He}$ would even put his fingers into the vomitus on the floor and re-introduce it into the mouth. Two months later also other food was "spit up" after almost each meal. The food would ascend into the mouth in small portions without difficulty, violence or nausea, about five minutes after the meal and after a few masticatory movements be reswallowed. A minute or so later it would reappear, and the repetitions of the act were kept up for one hour or longer, also during his playtime. There was little food lost in this process. Parts of food that happened to spill over the clothes were put back by him into his mouth with his fingers. There was no doubt but that the boy enjoyed ruminating. The food brought up never had any odor. After dinner, when the boy used to remain alone and awake for a longer period, there was usually an aggravation of rumination and it also was observed that the "spitting up" became worse whenever the father coughed and belched in the boy's presence, who also manifested a great imitative tendency. On the other hand, rumination was less likely to occur after breakfast when the boy was usually entertained and diverted by his father's fondling and playing with him; or when he was outdoors, which he enjoyed. His appetite and digestion during this whole time was perfect.

The boy is very well nourished, sturdy looking, has red cheeks, weighs at present (at the age of 18 months) 25 pounds, but is very willful, nervous, timid, easily startled and scared by noises and overcautious toward strange persons and objects. His mother considers him a very intelligent though "very queer" child.

Treatment.-Naturally the observation of the influence of psychic elements on his rumination suggested distraction in a systematic manner as a therapeutic measure. In order to deflect his attention intensely and permanently from his affliction various means had to be employed, as exemplified in the following procedures.

March 30, the first day of treatment: Soon after the breakfast, at $6: 15$ a. m., he began to ruminate as usually. This was immediately stopped when the mother energetically scolded and threatened him. She then sang to him

* Received for publication Aug. 5, 1920. 
and got him to sing with her for awhile; thereafter she amused him by questions that he would answer and continued diverting his mind by dressing him. Then the father undertook his amusement so that the boy's mind was permanently occupied for one whole hour. No rumination had occurred. At 10 a. m., after the bath, the boy was fed and put to bed where he fell asleep immediately without rumination. The next feeding was at $1: 15 \mathrm{p} . \mathrm{m}$. Immediately thereafter he was amused for about the first ten minutes by songs, in which he eventually joined. Thereafter he was given a new plaything, the novelty of which interested him intensely for awhile. When the novelty began to wear off, he was taken outdoors, which had been observed to have a tendency to lessen his rumination as stated before, no doubt likewise through diversion. No rumination occurred.

At $4: 45$ p. $\mathrm{m}$. water and orange juice were given. The mother at once sang to him and played on the piano, of which he always has been very fond, and later she played with him. No rumination occurred.

Supper was at $5: 30 \mathrm{p} . \mathrm{m}$. He soon ruminated three times, but stopped when scolded. Talking to or continuously playing with him prevented him from ruminating entirely until he finally was put to bed and fell asleep. immediately.

During the following few days identical pedagogic-therapeutic procedures were taken. March 31 rumination took place four times after dinner and once after supper. April 1 and 2 it occurred only once after supper. Since that time he has never ruminated or regurgitated. But he began chewing his sleeves or other parts of his garments within reach of his mouth.

In this case the persistent vomiting and regurgitating of soup with angry refusals, apparently due to aversion to it, may be taken as an early symptom of a certain lability of the reflex mechanism of the pharynx, esophagus and stomach under conditions that point to the interference of a psychoneurotic element. The psychic factor also revealed itself by the fact that later, coloring the soup with a little milk induced this very willful, undoubtedly nervous boy to take it without further trouble. There was never any other disturbance of the gastro-intestinal tract. No doubt the responsiveness of the reflex apparatus rendered it possible that later the regurgitation of orange juice, perhaps at first accidental, should have repeated itself with such readiness, in the beginning only occasionally, but soon regularly. The juice being agreeable to him, he apparently learned to reswallow it readily. Such a selective regurgitation of a particular food is well known in the adult ruminant. By frequent repetitions of this process aided by the psychic factor, through facilitation of the nervous centers involved, regurgitation and reswallowing became a pathologic, well fixed nervous habit, a pathologic reflex, easily started and finally released also for gratification by other food. It is not without significance that after the cure the boy, in order to obtain some gratification, found a substitute in chewing his sleeves, for several weeks.

The conception of pathologic conditional reflexes in the sense of Czerny and Ibrahim brings rumination nearer our understanding; 
their nature and development was dwelt on by me in a former article. ${ }^{1}$ The abnormal motor process of a pathologic condition reflex often originates from local pathologic causes but nevertheless persists even after the subsidence of the primary pathologic stimulus as a kind of pathologic habit of the nervous system. The acts are then provoked by the physiologic stimuli of the daily life. A conditional reflex can be traced to the cooperation of a psychic factor with an ordinary unconditional reflex. There is no definite or characteristic anatomic basis for rumination and its essential initial phase, the regurgitation.

The few fluoroscopic examinations made in babies have demonstrated no gross deviations from the normal and findings of pylorospasm as in the cases of Lust ${ }^{2}$ and Aschenheim and in the one reported by me have only an indirect though important bearing. In such circumstances the rumination develops most probably as a secondary functional affection in consequence of the vomiting and regurgitating caused by these diseases. Similarly, "habitual vomiting" and pure regurgitation and vomiting due to chronic dyspepsia, especially often following ablactation, have been complicated by pronounced rumination. The original disturbance, anatomic or functional, sometimes, perhaps, very insignificant and thus easily overlooked, may act merely as an initial factor in the evolution of the pathologic complex of rumination. The members of the motor chain become firmly linked together as a complex and fixed through repetition and facilitation, possibly aided by the desire for gratification that lies in rumination, and may outlast the original affection, appearing then as an independent "neurosis."

The cooperation of an organic and neuropsychic component, combined in varying proportions, may be unmistakable in the development of rumination. In a number of cases it must be admitted, as Landé ${ }^{3}$ has pointed out, rumination has developed without a period of previous vomiting (cases of Wirtz, Puoliot). The basis, it seems, is a neuropathic constitution manifesting itself not only in the disturbance of the reflex processes of the automatism of the stomach but also other. wise. Indeed, the presence of various nervous symptoms has been noted by many observers. The psychic factor in my case, namely, the fondness for orange juice and other regurgitated food, suggests itself as a contributory factor.

We know also from observing ruminants that rumination is often enjoyed and that they may regurgitate and ruminate at will, starting the process voluntarily.

1. Strauch, A.: J. A. M. A. 65:678 (Aug. 21) 1915.

2. Lust: Monatschr. f. Kinderh. 6: 1911.

3. Landé: Monatschr. f. Kinderh. 14:196, 1916. 
A perfect dependency of regurgitation and rumination on will and intention $I$ repeatedly observed in a friend of mine, a merchant, aged 37 years, a man of unusual intelligence and learning. He has always enjoyed good health and digestion. He cannot recollect at what age his "peculiarity" started, but he remembers with certainty that when about 20 years old he could voluntarily and easily vomit or regurgitate food, and that often he did rechew and reswallow it. $\mathrm{He}$ thought it to be natural until told the contrary by his brother in law, who accidentally discovered his habit about that time. He also remembers that he often astonished his friends by the amount of beer he could drink without intoxication; for he readily would empty his stomach and begin anew to drink, his ability to regurgitate having been kept secret from friends and members of his family. Though ruminating was practiced more or less habitually at the time, at the present it occurs only infrequently, but always voluntarily, more or less consciously and he can easily desist from it, as, for instance, when in society. He would regurgitate and ruminate especially after a very heavy meal, or if he had eaten "food hard to digest," as, for instance, tendinous parts of meat, large pieces of potatoes, swallowed in a hasty meal, lettuce mixed with onions, parts of the stem of lettuce, tough fibers of string beans, the white skin of oranges and the skin of sausage. These parts have "a special irritating influence on his stomach, and cause him a peculiar sensation of fullness but no pain or feeling of pressure." He notices "that the food is indigestible." Under such circumstances, he would rechew and reswallow the regurgitated food but spit out the "indigestible parts, as fibers, etc." and stop regurgitating when no more indigestible particles are felt in the ascending food, or the latter begins to taste sour. He also spits out any desired amount of regurgitated food whenever he thinks "it would be better for him to empty the stomach" or if he fears "the food may not agree with him." He would, after an excessive consumption of coffee during a social evening, out of fear that it would disturb his sleep, regurgitate and spit it out immediately after his arrival at home. Regurgitation is easier with a full stomach than with a partly filled one; therefore, to facilitate it in the latter case, he drinks water or swallows air.

Recently I had the opportunity to observe him after a heavy Sunday dinner at the home of a mutual friend. During almost a whole hour, over and over again, complying with my wish, did he demonstrate his ability to regurgitate and ruminate at will. Probably from mental inhibition due to embarrassment he had to drink water in order to facilitate the first act, but thereafter there was no difficulty in bringing up the food as often as he was asked. A very slight strain with the lower part of the abdomen sinking in and the stomach region bulging 
out for a moment, while the glottis is closed, and, as he stated, a kind of "pressing up" is done, sufficed to bring the food up promptly. This was somewhat rechewed and then reswallowed; the fibers of stringbeans and celery and parts of lettuce were spit out. $\mathrm{He}$ considers his ability to regurgitate a decided advantage, and attributes to it the preservation of his health during a long stay in the tropics despite his overindulgence in frequent club banquets. It is noteworthy that he never was seasick on his many transoceanic voyages.

Imitation in a number of cases has led to regurgitation (Bruns) and also rumination. Freund and Koerner reported two children, aged 3 and 6 years, respectively, who learned this habit from a ruminant governess, but who were soon cured after her dismissal.

As is well known, stimulation of a certain nervous center by peripheral irritation may inhibit other central functions under ordinary physiologic conditions. The experiments of Pawlow's laboratory demonstrated that a conditional reflex likewise may be inhibited by the introduction of a new stimulus. In a similar manner we succeed occasionally in eliminating the pathologic nervous symptom complex entirely, or in part, by the interpolation of an unwonted factor into the reflectoric motor process, as, for instance, in ruminating or habitually vomiting infants (Meyerhofer, ${ }^{4}$ Huldschinsky) by feeding thick gruels. Though some authors believe that gruels lessen regurgitation by irritating the gastric mucosa less or on account of the consistency, Schippers " emphasizes the psychic factor of a certain food, as his second patient ruminated every food regardless of its consistency, except bean puree. Likewise, the idiotic ruminant of Landé ruminated gruels but kept down vegetables. Schippers' two patients ceased ruminating as often and as long as they were in the roentgen ray room, so that repeated attempts to study the process of rumination roentgenologically failed, it having been impossible to accustom the babies to the room.

Scolding and threatening may stop rumination at least for a short time. We act on a similar physiopsychologic principle if we introduce therapeutically diversion by sounds, play, swinging, change of surroundings as an inhibitory factor and succeed in making the ruminant baby or child desist from his pathologic habit. The less established and inveterate the pathologic mechanism is, the more prompt, ceteris paribus, will be the inhibitory and curative effect of the former upon the latter. This may explain the prompt therapeutic result in my case.

Wirtz and later Goett ${ }^{6}$ and Landé observed the beneficial effect

4. Meyerhofer: Therap. Monatschr., April, 1912, p. 262.

5. Schippers: Ztschr. f. Kinderh. 10:92, 1914.

6. Goett: Ztschr. f. Kinderh. 16:177, 1917. 
of distracting play, and Bruening ${ }^{7}$ noticed a child almost immediately cease ruminating when a change of surroundings was effected by giving the patient into individual care. In a case of Somersalo ${ }^{8}$ nibbling or sucking a piece of zwieback after meals made the child, who also was given gruels, forget his rumination habit by distraction. However, there are a number of cases that resisted the most varied dietary and intentional or unintentional psychic therapy.

Landé ${ }^{3}$ considers rumination in certain cases as "cage disease," long stay in a hospital without diversion and entertainment, the ennui of isolation occasionally creating the affection in her view. Transfer of the patient among lively children, etc., may prove effective therapeutically.

It has long been known that in some adults diversion by animating conversation after meals inhibits rumination and its first phase, the regurgitation and that they may be able to suppress it voluntarily (autosuppression, Boas) the psychic factor of discipline being by all means the principal therapeutic agent. Ylppoe, ${ }^{9}$ in whose opinion rumination in infants is often a consequence of aerophagia and its accompanying regurgitation, places the baby on its abdomen in order to prevent air-swallowing during nursing, which position by distraction exerts a psychogenic therapeutic effect. In ruminants that soon became used to this new position and again began to ruminate, the necessary distraction was obtained by placing the children in the abdominal posture on a mobile suspension. The results were excellent, and the author recommends this method also in treating habitual vomiting.

In a ruminating girl, 5 months old, as reported by me, artificial obstruction of the nose by insertion of cotton after each meal while the baby was kept lying down on her back, interfered with rumination and caused discomfort so that she almost entirely ceased even attempting to ruminate, though various methods had previously been empled unsuccessfully. The regurgitation subsided gradually and ceased practically within two weeks. I was led to the systematic use of this "heroic" procedure by the observation that regularly, as often as the nose was pinched, experimenti causa, and nasal respiration thus obstructed, while the baby was kept lying on her back she at once resentfully stopped ruminating and swallowed the food in order to get air through the mouth. One could not help thinking that the child desisted from rumination eventually because of discomfort and urgency of air-hunger entailed by the act, and that after a sufficient

7. Bruening: Arch. f. Kinderh. 60:116, 1913.

8. Somersalo: Arch. f. Verdauungskrankh. 16:167, 1920.

9. Ylppoe: Therap. Halbmonatschr. 34:76, 1920. 
time regurgitation itself was given up, because it could no more lead to the pleasurable act of rumination at ease. Unfortunately, soon the baby contracted measles during a ward epidemic and died from complicating bronchopneumonia.

To obtain satisfactory results one must not forget that with nose obstruction solid or semisolid food brought up into the mouth would not to the same degree interfere with mouth breathing and be distressing in the upright posture during the act of rumination as would milk that fills up the mouth of a baby lying on its back.

In attacking therapeutically the last link in the chain of the motor complex, also the preceding links were being eliminated. The "logic" of this procedure is proven not only by the immediate results of repeated experimental nose obstruction and the eventual therapeutic success in my case, but is evident also to those who keep in mind the similar principle underlying the successful curative administration of bitter pills during meals in some adults, the intense bitterness of the drug in the regurgitated food inducing them to cease not only ruminating but also its first phase, namely, regurgitating.

In merycism in babies, associated with severe pylorospasm or a marked motor insufficiency with stagnation and fermentation or with organic disturbances, such as dilatation of the cardia or the lower part of the esophagus, neither psychic diversion nor nose obstruction will abolish the vomiting or regurgitation (the first and essential phase of merycism); in so far as it depends on these lesions it will still continue. The urgency of the organic component is simply beyond the reach of a psychic influence. Here the therapy naturally must first be aimed at these organic lesions or other anomalies. In the adult ready cures of rumination have repeatedly followed the cure of associated gastro-intestinal diseases.

In connection with the observations as to the rôle the psyche may play in the inhibition of rumination and regurgitation, I wish to submit the following highly interesting observation of a complete cessation of this affection during pertussis and a subsequent cure (from my private practice).

CASE 2.-History.-James Q., born Oct. 3, 1917, was a very nervous, irritable, stubborn, but physically well developed boy. Both parents are likewise very nervous and his three sisters had suffered from enuresis nocturna. At the age of 1 year (middle of October, 1918) he suffered from influenza with pneumonia and has often since that time had convulsions, which under bromin therapy became finally less frequent. For a period bromin was discontinued on account of symptoms of intoxication.

In May, 1919, the boy began frequently to "spit up" his food. Whether this was due to large dosages of bromin or not cannot be decided with certainty, as I rarely saw the boy during this period. In August, 1919, I found that he ruminated; the exact beginning of the act could not be determined. After almost every meal, even small ones, the boy would bring up the ingested 
food; liquids, such as milk, were borne much better, and if brought up, were reswallowed immediately; semisolid or solid foods were reswallowed after a few masticatory movements.

The rumination was kept up in frequent repetitions and much enjoyed. During some periods conditions would improve, and there was one week when he did not ruminate at all; however, during other periods the trouble would be aggravated and he would ruminate for two or more hours after each meal, even shortly before the next one and practically the whole day during his play with other children. This happened especially during the day previous to an epileptic seizure, when he was very irritable, and during constipation. There was for a long time a very rancid odor to the regurgitated food. Only rarely a real vomiting of any violence occurred; but whenever food would spill over, for instance on the highchair, the boy would put it back into his mouth with his fingers or the spoon and re-eat it despite its rancidity. If scolded he would stop ruminating for a moment, resentfully run away and recommence ruminating.

Treatment.-Various quantitative and qualitative changes of diet, long and short intervals, magnesium, etc., failed to have any noticeable effect. The nervous tension of the home life, through lack of cooperation, rendered pedagogic therapy futile. In April, 1920 the boy contracted pertussis together with the other children of the family. He suffered the most. The paroxysms were very frequent, violent and accompanied by vomiting that continued to the end of May. His general condition, however, was little affected thereby. The remarkable feature was that the boy during this illness had entirely ceased ruminating. Only on May 9 and 19 did he ruminate a very little after breakfast and again in the last week of May and the first week of June. His mother volunteered the remark, "he tried, but did not know how to do it any more." Since that time no more rumination has occurred.

The assumption that rumination should have stopped from lack of stomach contents on account of frequent vomiting is, of course, not tenable, especially in the presence of the fact that the boy's physical condition was good, no signs of underfeeding existing. Most probably it was the mechanical interference with easy and comfortable rumination by the violence of real vomiting and expectoration during the paroxysms, together with his own and his sister's suffering, and the fear of new attacks becoming the center of his attention (as it was so with his worried parents) that crowded out the former neurotic manifestation with the same psychic force as an "event" occasionally has done in adult ruminants. This case is the more noteworthy, since pertussis has been observed to have led to rumination, evidently by the accompanying vomiting.

A similar observation of a curative effect of an intercurrent disease on rumination has been published by Wanietschek. ${ }^{10}$ The boy ruminated from the second month of life unceasingly and resisted various treatments, until a temporary cessation took place in his seventh year due to adenectomy. In his eighth year of life a complete and permanent cure occurred in connection with a transitory postdiphtheritic deglutition paralysis. The author ascribes this cure to autosuggestion, maintaining that the boy, much troubled by the disturbance of the

10. Wanietschek: Jahrb. f. Kinderh. 82:66, 1915. 
pharynx (deglutition mechanism), had to avoid the regurgitation of food as much as possible. Schippers observed rumination in two babies to cease temporarily during dyspepsia with meteorism.

That nervous habits may be given up during an illness which is accompanied by malaise, is well known. I have only lately seen in my Cook County Hospital service a 12 months old head roller completely cease this stereotypia during measles. Whether this was permanent, I did not ascertain, as the child left my observation too early, having been transferred to the Contagious Hospital. 